\title{
Política, alegoría y disenso en la poética de Ed- gardo Antonio Vigo (1960 - 1976)
}

Ana L. BUGNONE*

Universidad Nacional de La Plata-CONICET (Argentina)

\begin{abstract}
RESUMEN. En este trabajo se analizan algunas obras creadas por el neovanguardista argentino Edgardo Antonio Vigo entre 1960 y 1976, desde una perspectiva que relaciona su producción artística con la teoría de Walter Benjamin -en especial, el concepto de alegoría- y la de Jacques Rancière referida a la idea de régimen estético del arte. Del análisis de poesías visuales, acciones y objetos de Vigo surge una fuerte vinculación entre arte y política, más que por la tematización de esta última por la forma que presentan y la reacción que provocan. Como en la alegoría de Benjamin, estas obras rompen con la idea de universal explicativo a través de su factura con fragmentos. Asimismo, su carácter de disenso se evidencia a través del cuestionamiento a las formas habituales y consensuadas del orden social, así como al lenguaje artístico tradicional. Resulta así una compleja combinación de elementos que permiten analizar parte de su poética, haciendo hincapié en su aspecto político.

Palabras clave: Edgardo Antonio Vigo, neovanguardia, arte, política, década de los sesenta, década de los setenta.

ABSTRACT: In this paper we analyze some works created by the Argentinian neo-avantgardist Edgardo Antonio Vigo between 1960 and 1976, from a view that relates his artistic production to Walter Benjamin's theory - specially his concept of allegory - and Jacques Rancière's one about the idea of art's aesthetic regime. From the analysis of Vigo's visual poems, actions and objects it arises a strong connection between art and politics, rather due to their shape and to the reactions they provoke than to politics' thematization. Like in Benjamin's allegory, these works break the idea of explanatory universal since they are made with fragments. Furthermore, their dissent feature becomes evident trough its questioning to forms of the social order which are habitual and on which there is consensus, as well as to traditional artistic language. Thus, there is a complex combination of elements which allow the analysis of part of Vigo's poetics, laying emphasis on its political aspect.
\end{abstract}

Key words: Edgardo Antonio Vigo, neo-avantgard, art, politics, sixties, seventies.

\section{INTRODUCCIÓN}

El artista neovanguardista Edgardo Antonio Vigo (1928 - 1997) produjo obras rupturistas frente a los cánones de la institución arte, especialmente en relación a los

* Centro de Estudios de Teoría y Crítica Literaria / Instituto de Investigaciones en Humanidades y Ciencias Sociales (IdIHCS) 
roles asignados tradicionalmente al autor, la obra y el público. El análisis de algunas de sus obras producidas entre 1960 y 1976 permite encontrar vinculaciones diversas, no esquemáticas ni fijas con la política. Este trabajo se centrará en una de esas relaciones posibles: su politicidad más allá de una relación temática con la política que parte de la materialidad de la obra y de la forma en que está construida ${ }^{1}$.

Las múltiples relaciones posibles entre el arte y la política en la obra de Vigo forman un entramado, que implica nexos múltiples y entrecruzados. Si bien el artista produjo obras en las que utilizaba acontecimientos políticos de relevancia nacional e internacional (entre ellos, el Cordobazo ${ }^{2}$, la masacre de Trelew $^{3}$, la figura del Che, la Guerra de Vietnam), también se vinculó con la política de otros modos menos explícitos pero igualmente relevantes. Allí se centrará este trabajo, aunque corriendo el riesgo de que la separación analítica de dimensiones de un objeto, provea de conclusiones parciales o sesgadas.

\section{NEOVANGUARDIAS ARTÍSTICAS EN UN CLIMA DE CAMBIOS SOCIALES Y POLÍTICOS}

En la ciudad de La Plata, entre los '60

\footnotetext{
${ }^{1}$ Una primera versión de este trabajo fue presentada en las V Jornadas de trabajo sobre Historia Reciente, organizadas por la Universidad de General Sarmiento en Los Polvorines (Argentina), entre los días 22 y 25 de junio de 2010. Agradezco los comentarios que realizó Ana Longoni sobre el trabajo.

2 El "Cordobazo" fue una rebelión popular desencadenada en la ciudad de Córdoba (Argentina) en mayo de 1969, donde confluyeron obreros, estudiantes y ciudadanos en general, para hacer frente el represivo gobierno de Juan Carlos Onganía. Culminó con decenas de muertos y centenares de detenidos.

${ }^{3} \mathrm{La}$ "Masacre de Trelew" fue el asesinato de 16 presos políticos, militantes de organizaciones de izquierda, el 22 de agosto de 1972, durante la dictadura de Alejandro A. Lanusse.
}

y los '70, se desarrollaron agrupamientos de artistas que conformaron neovanguardias. La neovanguardia, en general, es un agrupamiento de artistas que retoma los procedimientos de vanguardistas históricos, es decir de los años '10 y '20, tales como el collage, el ensamblaje, el readymade, la retícula, la pintura monocroma y la escultura construida ${ }^{4}$. En el proceso de constitución de neovanguardias en La Plata, numerosos artistas emprendieron programas de rupturas. Operó en estos grupos una radicalización de las prácticas artísticas a través de la confrontación con la tradición modernista de la autonomía de la obra de arte, así como con los modos dominantes de concebir las relaciones entre autor, espectador, institución y esfera social. Esos cuestionamientos se materializaron en obras que planteaban varios puntos de quiebre. Por un lado, se produjo la salida de los museos a la calle a través de la presentación de obras en espacios públicos y el ingreso de las problemáticas políticas al museo o las exposiciones. En segundo lugar, se intentó la supresión de la autonomía y de la consagración del autor a partir de la participación del público en la concreción de la obra, así como la ejecución de producciones colectivas entre artistas. En tercer lugar, se utilizaron materiales efímeros, de desecho, chatarra, partes de artefactos, así como obras de temporalidad acotada que duraban mientras la acción estaba desarrollándose. Finalmente, se produjeron obras de arte que salían de los cánones de la plástica y la poesía: poesía visual, objetos, acciones, tarjetas, arte-correo, revistas-sobre, manifiestos y otros escritos.

El campo artístico de esa ciudad, si bien estaba conformado por las instituciones artísticas y sus patrones clásicos, también daba lugar a un clima de creación distanciado de las pautas tradicionales del

\footnotetext{
${ }^{4} \mathrm{H}$. FOSTER, El retorno de lo real. La vanguardia a finales de siglo, Madrid, 2001.
} 
arte. El desarrollo cultural activo estaba centrado en la gran cantidad de jóvenes atraídos por la Universidad y sus colegios, con profesores que instaban a la experimentación y la renovación. Dos instituciones influenciaron fuertemente la producción artística de la época: la Escuela de Bellas Artes, perteneciente a la Universidad Nacional de La Plata y el Museo Provincial de Bellas Artes. Algunos de los profesores de esta Escuela contribuyeron a la formación vanguardista no sólo dentro de la institución, sino también de modo informal fuera de ella. En el Museo, espacio de visualización y consagración de artistas, se dio lugar a la presentación de obras de las nuevas tendencias en el arte, como el Grupo Sí, el Movimiento de Arte Nuevo (M.A.N.) y más tarde, de artistas del Instituto Torcuato Di Tella. El hecho de que la prensa y el público rechazaran varias de estas presentaciones, así como las de Vigo, da cuenta del grado de ruptura que representaban para la época sus producciones.

De un modo más general, los cambios producidos en este campo en la década de los '60 están marcados por el proceso de modernización cultural que incluyó desde cuestionamientos a la moral sexual hasta la aparición de revistas que cambiaron el modo de hacer periodismo en Argentina. Del campo intelectual emergió la idea de "intelectual comprometido", de acuerdo con la idea sarteana de compromiso con el pueblo y con el antiintelectualismo creciente, que apuntaba a la acción concreta más que al desarrollo de las ideas.

La experimentación en el arte fue otro de los aspectos de aquélla renovación más general, y puede ubicarse uno de sus centros más importantes en la Capital Federal, representado por el Instituto Torcuato Di Tella. Se trataba de un espacio de aprendizaje y creación, tendiente a producir obras en el país de acuerdo a los reglas del arte de vanguardia internacional. Ubicado en lo que se llamó la "manzana loca", estaba rodeado de galerías, bares e instituciones culturales que representaban lo nuevo en el arte. Sus exposiciones y premios, que apoyaban y consagraban a jóvenes artistas, intentaron ubicar a Buenos Aires como uno de los centros de arte en el mundo.

A fines de la década, un clima de movilización política y protesta social iba gestando la idea de que era el compromiso político el que daría sentido a las prácticas sociales. En ese proceso, varios artistas encarnaron una radicalización de sus propuestas estéticas y políticas. Éstas fueron, en general, reprimidas por el gobierno de Onganía ${ }^{5}$ y por la misma institución artística. Se conformaron en Argentina, de este modo, grupos que intentaban conciliar sus intereses estéticos con sus posicionamientos políticos de reclamo y oposición al régimen tanto institucional como gubernamental. Algunos de estos artistas terminaron conformando los grupos de Rosario y Buenos Aires que organizaron y expusieron el emblemático proceso colectivo "Tucumán Arde" en 1968.

La situación de este campo con propuestas cada vez más intransigentes, se dio en un contexto general de politización de la sociedad. Desde que el golpe de estado del '55 dio por terminado un ciclo de gobiernos peronistas $^{6}$, e intentó liquidar al amplio

\footnotetext{
5 Juan Carlos Onganía fue un presidente de facto que ocupó el poder entre 1966 y 1970. Su gobierno, autodenominado la "Revolución Argentina", implementó medidas represivas en lo económico y en lo político. Se destacó por su actitud especialmente autoritaria en las universidades y hacia la clase obrera.

${ }^{6}$ Juan Domingo Perón fue elegido presidente por dos períodos consecutivos, 1946 - 1952 y 1952 - 1958 y luego en 1973. Su política, fuertemente vinculada a la acción de los trabajadores, fue ampliamente avalada por ese sector y parte de la clase media. Durante su gobierno amplias masas de trabajadores se incorporaron a la política nacional y sindical. Resistido por sectores de la Iglesia y por quienes habían perdido
} 
movimiento justicialista, un proceso de politización y progresiva radicalización fue la respuesta y contracara de éste y los sucesivos proyectos políticos. Casi dos décadas signadas por la proscripción del partido mayoritario, fueron generando resistencias políticas, sindicales y sociales en general. La idea de revolución que, a partir de la Revolución Cubana, parecía haberse convertido en una posibilidad concreta, marcaba cada paso de los grupos que conformaron la "nueva izquierda". A ello se suma la renovación de la doctrina de la iglesia católica que congregó no sólo a los religiosos sino también a grupos de jóvenes dispuestos a involucrarse en tareas barriales, solidarias y luego, más decididamente políticas. A medida que avanzaban los '60 las organizaciones armadas crecieron un número $\mathrm{y}$ en diversidad. Ya no se trataba sólo de una respuesta a la proscripción del peronismo, sino de una propuesta de cambio radical a través de la lucha armada.

En estos años, entonces, se configuraron grandes cambios políticos que van desde la participación masiva de los estudiantes y obreros en las protestas, hasta la idea de lucha armada, en medio un sistema político autoritario o semidemocrático (como los casos de los presidentes Frondizi e Illia, elegidos con el peronismo proscripto). Mientras se bloqueaban los accesos institucionales a la política, ésta se escurría por las grietas que dejaban los gobiernos más o menos represivos. Y su emergencia, está claro, no iba a ser pacífica. Es en este escenario que la cultura participó del proceso no sólo como respuesta a las demandas de la política, sino como parte que lo conforma, generando nuevas preguntas, representaciones y disposiciones a través de amplios cuestionamientos a los condicionamientos estéticos, institucionales y canónicos, así

privilegios económicos y políticos, fue derrocado por un golpe de Estado en 1955. como incorporando nuevas lecturas teóricas y miradas del mundo.

\section{VIGO Y LA DESESTRUCTURACIÓN}

Vigo egresó de la Escuela de Bellas Artes de La Plata y produjo obras desde los '50 hasta la década de los '90. Este trabajo se ocupa de sus producciones entre 1960 y 1976. El período seleccionado implica el recorte de un tiempo convulsionado artística y políticamente, marcado por el avance del arte experimental de varios grupos (que abarcan desde los artistas del Di Tella hasta los colectivos que conformaron la muestra Tucumán Arde) así como por la radicalización política en Argentina.

El artista platense era grabador, pero utilizó la técnica fuera de los cánones establecidos, interviniendo el papel con cortes, trazos, letras y otras figuras, así como intentando socializar esta práctica poco usual fuera de la institución artística. Abarcó varias áreas: poesía visual, objetos, acciones, pinturas, grabados. Vigo estuvo, desde los orígenes de su producción, ocupado en la problemática de la participación del público. Muchas de sus obras requerían la intervención de aquél para poder concretarse: mirar por el agujero de una hoja, demarcar un espacio con tiza en una plaza, asistir a un señalamiento, armar una poesía, eran acciones que el público debía realizar para pasar, como sostenía Vigo, de la pasividad a la actividad. Luego de su viaje a París, en el que tuvo contactos con los resabios de las vanguardias históricas, se propuso romper la distancia entre el artista, la obra y el público, así como entre la obra y la vida. Pueden verse estos intentos en la necesidad de participación del público para la producción o culminación de las obras, así como en la utilización del espacio público como territorio para la realización de acciones. Entre 1968 y 1969 produjo una declaración titulada "Hacia un arte tocable". Allí Vigo expresa su propuesta de realización 
de un arte que se contacte con el público "epidérmicamente", alejado de las elites, los museos y las galerías, a través el uso de materiales "innobles". Las vías de conexión con ese público podían ser -según el textoel absurdo, lo lúdico o la ocurrencia, para generar finalmente una acción, en lugar de una contemplación.

Creó también objetos, construidos en su mayoría con fragmentos de otros objetos, artefactos, máquinas. Entre ellos, inventó en 1960 la Bi-tricicleta ingenua (con ruedas incapaces de rodar) que, si bien era un objeto artístico, el mismo Vigo intentó hacer funcionar. Otros objetos de este tipo son el Palanganómetro mecedor (que no se mece) para críticos de arte (1964) y el Objeto lumínico (1968-69).

En 1962 organizó la Revista Diagonal Cero (DC), cuyos 28 números se publicaron hasta 1968. Esta revista fue clave para el desarrollo de la poesía experimental en Argentina y en América Latina. Tenía un formato de carpeta cuyas hojas sueltas permitían el intercambio de orden o el desglosamiento de la misma. Se utilizaban los calados, huecos y cortes para complejizar la relación entre el espacio, el color y la forma, incentivando una propuesta de acción lúdica y creativa por parte del receptor (Fig. 1). Se publicaban obras plásticas y literarias, fragmentos de textos de vanguardistas, manifiestos. Con el antecedente de la poesía concreta brasileña, incorporó allí la poesía visual y los que llamó "poemas matemáticos". Con la poesía visual experimentó la ruptura del lenguaje literario que provenía de las vanguardias de principios del siglo XX y, cruzándolo con la plástica, desmanteló la estructura del verso, usó letras, palabras, números y la tipografía como formas visuales. Más tarde, en 1971 editó y produjo otra revista-sobre de poesía visual, con manifiestos, señalamientos y escritos, Hexágono, cuyos 13 números se editaron hasta 1975 y donde la situación política y social se ve reflejada a través de menciones directas o indirectas de algunos acontecimientos, pero manteniendo también algunas señales estéticas de confrontación con los lenguajes plástico y literario tradicionales.

En el año 1968 inició los señalamientos: acciones que consistían en destacar un objeto, hecho o situación elegidos por el artista. Realizó señalamientos en la vía pública, en una plaza, en la portada de DC, en el zoológico de La Plata, en el río de la Plat, entre otros (Fig. 2). En algunos casos lo realizaba con público y en otros, sólo con un compañero. El público no debía realizar una acción en el sentido de ejecución de un movimiento, sino que se buscaba la generación de un extrañamiento y un cambio en la mirada sobre lo que se estaba señalando. En consonancia con la ruptura que se propone de los cánones del arte, estas acciones implicaban des-ubicar espacios y objetos, desestructurando la experiencia de lo cotidiano y la propia condición de obra de arte.

\section{DE LA ALEGORÍA AL DISENSO}

Vigo tuvo acercamientos a un "arte político", entendido como arte crítico que intenta intervenir en el mundo a partir del uso de la política como tema de la obra, así como por la incorporación de ciertos hechos políticos de relevancia nacional ${ }^{7}$. Sin negar la importancia de estas producciones, la relación entre el arte y la política que in-

\footnotetext{
${ }^{7}$ Por ejemplo, en la imagen 2 puede verse el Señalamiento 11. Souvenir del dolor, donde el artista hace referencia a la "Masacre de Trelew". Nótese, sin embargo, que esta incorporación de un acontecimiento político a la acción artística, lejos de reproducir la fórmula panfletaria o didactista, apela a la experiencia de la percepción e interpretación del público, sin ofrecer un discurso acabado que explique cómo el sistema -en este caso, del estado represivo- ejerce la dominación. Por el contrario, la forma en que está realizada la obra de arte o acción, descoloca a un espectador dispuesto a recibirla pasiva o acríticamente.
} 
teresa explorar en este trabajo es una relación menos explícita, en tanto no se trata de una dependencia temática. A partir de la experimentación en el arte, Vigo propuso lo que llamó un "arte revulsivo", que apele a romper con el orden de la cotidianeidad, desestructurando lo cristalizado en la percepción y vivencia cotidianas. Partiendo de esta mirada sobre su obra, se intentará definir en qué consistió esta otra relación con la política a la luz de la teoría de Walter Benjamin sobre la politización del arte y en consonancia con la propuesta de Jacques Rancière para pensar las relaciones entre estética y política.

Benjamin analiza los cambios históricos que se produjeron en la producción y recepción de la obra de arte, especialmente a partir de las modificaciones de sus cualidades estéticas como la originalidad y autenticidad, que la han transformado en un vehículo de comunicación política. No se trata de obras de arte con un tema político, sino de la forma específica en que están producidas. El concepto de alegoría desarrollado por Benjamin en "El origen del drama barroco alemán" explica esta última idea. La alegoría, a diferencia del símbolo, está hecha de ruinas, partes que constituyen sentidos ambiguos y no reconstruibles en un todo significativo. En la alegoría "la falsa apariencia de la totalidad se extingue", dice Benjamin $^{8}$. Wolin explica la idea de alegoría de Benjamin de este modo: "los significados de las imágenes alegóricas no son en absoluto autoevidentes, según la dinámica histórico-filosófica de la mirada alegórica del mundo, todo significado ha cesado de ser autoevidente" ${ }^{\prime \prime}$. Para el filósofo alemán, en un mundo que se ha reducido a ruinas y fragmentos, quien ocupa el lugar

\footnotetext{
${ }^{8}$ W. BENJAMIN, El origen del drama barroco alemán, Madrid, 1990, p. 169.

${ }^{9}$ R. WoLIN, Walter Benjamin, an aesthetic of redemption, California, 1994, p. 67 (traducción propia).
}

- de dar significado en ese "cosmos caótico" es el alegorista, dado que no hay representación de la unidad entre universal y particular, como ocurre en el símbolo. Así, la belleza de las obras de arte que, según la tradición del símbolo puede ser juzgada en base a criterios clásicos y definidos, deja de tener sentido en la alegoría. Se traslada, además, la comprensión de las obras a las circunstancias materiales en que fueron producidas.

La alegoría y el montaje, una hecha a partir de ruinas y el otro con fragmentos, son irreductibles a un todo explicativo y comprensivo. Se alejan, de este modo, de la ruta del pensamiento y la forma de conocimiento burgués-capitalista, representadas por la idea de símbolo y de progreso. Es a partir de estos medios que el arte se politiza. Frente a la "catástrofe única que amontona incansablemente ruina sobre ruina"10, la alegoría parece convertirse en una posibilidad de salida.

La politicidad de las obras de Vigo aquí consideradas puede ser contenida en este planteo, en primer lugar, a partir de la definición fundamental de que no es el tema sino la forma de las mismas la que define su política. Es por ello que se anunció al principio de este trabajo que no se hará foco tanto en las obras de "arte políti$\mathrm{Co}^{\prime \prime}$, sino en aquellas en las que esta relación va por otros carriles. De las formas que organizan estas obras emerge una politicidad emparentada con la alegoría, en tanto puede considerarse que están hechas de ruinas de lo cotidiano y fragmentos de lo decible.

Letras, números e imagen forman las poesías visuales de Vigo; algunas veces se agregan agujeros o pliegues que el lector

10 W. BenJAmin, Discursos interrumpidos. Madrid, 1982, p. 183. 
deberá abrir para completar, en un proceso compartido con el autor, la propia poesía. Mixtura dibujos con letras que parecen de molde y figuras en colores y compone, finalmente, una imagen que remite al dibujo técnico en el uso de líneas rectas y signos que aparentan rigidez en una configuración móvil (Fig. 3).

Vigo desarma la escritura a partir de la poesía visual, colocando signos que pierden racionalidad y funcionalidad, palabras aisladas. Compone una poesía que no sólo desestructura las reglas del lenguaje literario, sino que además genera una percepción corrida de su eje normal: una poesía que no puede leerse. Esto implica un des-encaje del orden que representan las reglas de la lectura, la escritura y la percepción, así como del significado de esas palabras, letras y números en la estructura de la lengua y la matemática. La poesía visual es, entonces, una ruina de sentido. Si se suma a ello que Vigo publicaba sus poesías en una revista formada por hojas sueltas, intercambiables, de distinto color y espesor, algunas veces caladas, agujereadas, señaladas, se intensifica la carencia de un orden predeterminado que provea al receptor de un sentido unívoco y lineal. No hay teleología ni progreso en la obra, en tanto no se proyecta a qué resultado puede arribar el receptor "leyendo" una poesía caótica y fragmentaria. En este sentido, a partir del trabajo de alegorista, resulta la ausencia de significado único, pues se ha desmembrando la relación de las palabras y expresiones con el todo.

Se trata, por un lado de la supresión de las reglas que estructuran los lenguajes visual y literario y, por otro lado, de la demanda de acercamiento hacia un público que deja de ser pasivo, activando un proceso de participación que determina la conformación de la obra. En el caso en que el "lector" de la revista DC debe ubicar su ojo en un agujero realizado en una de sus ho- jas, para mirar a través suyo y crear así su propia poesía, el receptor se transforma en actor de su creación. Asume así el público el rol del artista, al mismo tiempo que el artista pretende abandonar la firma de su obra, limitándose a dar escuetas instrucciones.

En la construcción que realizó Vigo de objetos "inútiles" a partir de trozos de otros, aparece nuevamente el fragmento. Una Bi-tricicleta que no funciona, un reloj que no marca la hora, un mecedor que no se mece, construidos con partes de otras máquinas, son artefactos en los que Vigo juega con elementos que parecen tener una funcionalidad, sin embargo ésta ha sido desmantelada, y se han transformado en obras de arte.

El Palanganómetro mecedor (que no se mece) para críticos de arte (Fig. 4) además de constituirse en un mensaje burlón para los críticos, es un constructo de partes de otros objetos: una silla, una palangana, caños, una cadena, una base de madera. Los fragmentos constituyen nuevos objetos que ya han perdido su referencia a otra cosa y estos objetos, convertidos en montajes, escapan a la remisión de una totalidad significativa. Abren la percepción a la multiplicidad de sentidos, descolocando de su lugar "natural" a objetos ahora impedidos de relacionarse directamente con un significado unívoco y habitual. No hay conexión directa entre el todo y la parte y, como expresa Benjamin, "el objeto es totalmente incapaz de irradiar un significado, un sentido; el significado que le corresponde es el que le presta el alegorista"11.

Hay aquí un punto de conexión entre la propuesta teórica del filósofo alemán y su par francés. Rancière presenta un modo de relación entre el arte y la política que

\footnotetext{
11 W. BenJAMIN, El origen... p. 177.
} 
llama "modelo de la eficacia estética". Según el autor "se trata de una eficacia paradójica: es la eficacia de la separación misma, de la discontinuidad entre las formas sensibles de la producción artística y las formas sensibles a través de las cuales ésta se ve apropiada por espectadores, lectores $\mathrm{u}$ oyentes. La eficacia estética es la eficacia de una distancia y de una neutralización" ${ }^{\prime 2}$. Se suspende así toda relación directa entre intención del autor y acción de la comunidad, al mismo tiempo que opone a la mediación representativa una "disyunción radical". Esta eficacia estética es, para el autor, la "eficacia de un disenso", entendiendo por disenso lo que está en el centro de la política, es decir, el conflicto por los diversos regímenes de sensibilidad y su reconfiguración. Estos regímenes determinan una división de lo sensible: un "reparto de partes y lugares" 13 que instituye qué objetos y sujetos están designados por las leyes, qué tipos de relaciones se establecen entre ellos y qué sujetos son aptos para designar esos objetos. La política, entonces, permite romper con ese orden "natural" que Rancière llama policial- para redibujar el espacio de las cosas comunes. El papel del arte en este sistema implica la "disociación de un determinado cuerpo de experiencia"14 $\mathrm{y}$, en ese sentido, se trata de un disenso que permite transformar la normalidad, la división de lo sensible.

Podría pensarse que alegoría y disenso van en una misma dirección. En la experiencia estética como experiencia del disenso, "las producciones artísticas pierden en ello su funcionalidad, salen de la red de conexiones que les otorgaba una finali-

${ }^{12}$ J. RANCIERE, El espectador emancipado, Buenos Aires, p. 58.

${ }^{13}$ J. RANCIÈRE, La división de lo sensible. Estética y Política, Salamanca, 2002, p. 3.

${ }^{14}$ J. RANCIERE, El espectador..., p. 62. dad, anticipando sus efectos" 15 , de modo que en la ruptura con la distribución de lo sensible, la obra de arte es también una disrupción con los significados habituales y consensuados. Aquí, como en Benjamin, es la forma la que origina su política: lo que para el primero es la forma fragmentaria de la alegoría, para Rancière es la forma del disenso. Pero, además, ambas involucran un modo de experiencia que rompe con los sentidos disponibles en un momento histórico dado. La ausencia de remisión de la parte a una totalidad es también una ruptura con el orden de lo sensible, porque esto último implica un corte en la relación con un todo significativo que da sentido a cada una de las partes que lo componen, las jerarquiza, la ubica en tiempo y espacio. $\mathrm{Si}$, a partir de la experiencia estética, cada parte puede vincularse de un modo distinto al establecido por el orden "natural", reconfigurando lo sensible, está, al mismo tiempo, desarticulando la relación con la totalidad. Es así como alegoría y disenso apuntan a un mismo proceso.

El primer señalamiento de Edgardo Antonio Vigo ocurrió en 1968: “Manojo de semáforos", consistió en convocar al público a una esquina de la ciudad de La Plata a mirar un semáforo a través de una invitación que contenía un "manifiesto" (Fig. 5).

El artista, que no concurrió al encuentro, dejó como instrucción en el "manifiesto" la proposición de experimentar una vivencia estética sobre el señalamiento del semáforo. La cita fue en una esquina muy transitada por tratarse de un cruce de calles importantes (calles 1, 60 y Diagonal 79) y espacio de realización de trámites burocráticos y policiales, dado que allí se encuentran en Registro Provincial de las Personas y la División de Infantería de la Policía de la Provincia de Buenos Aires. Sin embargo,

${ }^{15}$ Ibidem, p. 62. 
el público fue convocado para observar un semáforo, aquello que cotidianamente tenía una funcionalidad específica, se transformó en objeto de atención desde otra mirada. Tres años después, Vigo escribía "[se propone] una revulsión que no sea únicamente formal y estética, sino un cambio formal de vida".

En este señalamiento a partir de la búsqueda de modificación en la relación habitual con la experiencia cotidiana, la acción se ha convertido en disenso, y el semáforo, en alegoría. El arte ha fijado de otro modo "la red de relaciones entre espacios y tiempos, sujetos y objetos, lo común y lo singular"16. Esta experiencia cambia la configuración de lo sensible, en tanto el orden predispuesto se modifica en relación a la acción que reubica esas redes. Los que miran son otros que aquellos que diariamente transitaban; el semáforo también ha modificado su estado de objeto técnico. Todo ello ocurre en un espacio que ha transmutado su condición de calle, semáforo, registro, policía, convirtiéndose en emplazamiento de extrañamiento para el desarrollo de una actividad que escapa a lo establecido por el régimen. El tiempo se detuvo de la vorágine de trámites y tránsitos para pasar al momento suspendido del señalamiento. Ha hecho "saltar el continuum de la historia" en "un presente que no es transición, sino que ha llegado a detenerse en el tiempo" ${ }^{17}$. Aquí no hay transición porque con el señalamiento se ha eliminado el sentido ordinario de las cosas y su devenir progresivo en un tiempo homogéneo. $\mathrm{Al}$ mismo tiempo, la transformación del objeto semáforo en otra cosa hace imposible remitir su significado a un universal explicativo. Para Benjamin, en manos del alegorista, "la cosa se convierte en algo distinto y él habla

\footnotetext{
16 J. RANCIERE, «La política de la estética» Otra Parte, $\mathrm{n}^{\circ}$ 9, 2006, p. 3.

17 W. BENJAMIN, Discursos... p. 189.
}

así de algo diferente" ${ }^{18}$. En efecto, el semáforo deja de ser un ordenador de tránsito, $y$, la acción que ha reordenado la experiencia sensible, le impide seguir siendo lo que era.

\section{REFLEXIONES FINALES}

El rechazo al realismo y a su representación mimética de la realidad, común en las vanguardias históricas, fue retomado por Vigo en sus obras y expresiones. En 1956, durante una entrevista en Radio Universidad, dijo "el arte siempre será condicionado a una REPRESENTACIÓN que puede ser matemática, abstracta, etc., pero siempre era representación. En vez, el NOARTE entra en el campo creador, creación no es representación". En esta propuesta de anulación de la representación, Vigo es el alegorista negando la relación de partes que han dejado de ser autoevidentes con el universal. Para Vigo no hay representación y, puede decirse con Benjamin, no hay símbolo, porque ha dado lugar a la creación que es, por el contrario, la construcción de obras con fragmentos irreductibles a la totalidad significativa. Para la recepción de éstas se debe salir recogimiento para poder acceder al shock que produce el caos de fragmentos. Este shock es lo que Vigo llamó un "arte revulsivo", que resulte provocador por romper con el orden conocido y convenido de la relación de la obra con el mundo, y de los significados aceptados socialmente en un momento dado: la actitud crítica que Vigo quiere provocar en el público, convertido ahora en partícipe indispensable para la realización de las obras o al menos para conferirle un sentido que el artista deja disponible.

Al mismo tiempo, en el "no-arte" que propone Vigo no hay orden que coordine la relación entre las partes más que el que le da el alegorista. Éstas se disponen de mane-

\footnotetext{
${ }^{18}$ W. BENJAMIN, El origen... p. 177.
} 
ra desordenada, como "imágenes que sedimentan en una multitud de metáforas caóticamente dispersas"19. Así, con la alegoría, el régimen de la sensibilidad se pone en cuestión o deja de funcionar como estatuto de normalidad. Dice Benjamin que "cada persona, cada cosa, cada relación puede significar otra cualquiera" 20 , lo que los hace inconmensurables con las cosas profanas. $\mathrm{Si}$ la organización de estas cosas profanas puede ser identificada con lo que Rancière llama orden policial, que prescribe la disposición de cada sujeto, objeto y sus relaciones, la alegoría representa un disenso frente a ese régimen: hay una "distorsión" tanto en una parte que no hace referencia al universal, como en la irrupción de la voz del que no tiene logos y de la parte del que no tiene parte. De este modo, la politicidad de estas obras parte de la alegoría y el disenso. Ambos resisten a la normalidad: violentan a la unidad de universal y particular, y así compelen a desarticular el régimen de la sensibilidad.

Esta política del arte, ubicada en el contexto de cambios culturales y políticos de la época, puede generar un desplazamiento oblicuo, que, al par que se daba la relación lineal del arte pedagógico (de la obra a la politización de la sociedad), se plantea como una relación donde el arte provoca un movimiento que, desencajando las reglas de los lenguajes y la experiencia, configura posibilidades para el surgimiento de nuevas miradas sobre el mundo, al ritmo que en otros ámbitos de la sociedad la política aparecía desbordando los límites impuestos, radicalizándose con un objetivo revolucionario.

Puede pensarse que estas transformaciones son políticas, en tanto a través de las rupturas que plantean, no sólo con los cánones del arte, abren paso a la pregunta por las posiciones que ocupan sujetos $y$ objetos, tiempos y espacios en una determinada red de relaciones sociales. Cuestionan de este modo el orden de lo existente que representa la normalidad, el orden de lo cotidiano con sus sentidos habituales y disponibles, frente al cual el "régimen estético de las artes" proporciona una nueva política. En esta clave, las producciones de Vigo representan un disenso con el orden normal, un corte con los significados comunes de las cosas, entre las que podemos incluir las mismas obras de arte. En ese disenso invita a un desborde, más allá de las reglas del campo artístico, con las reglas sociales y culturales. En ese sentido, puede ubicarse en estas obras una política que no cuestiona el orden por la utilización de una temática política, sino por la forma de su propia construcción. La desestabilización de los roles de autor y receptor, así como de las reglas del campo del arte, permiten la generación de nuevas subjetividades políticas preparadas para una nueva mirada del mundo. Vigo, en 1971 escribió "No debemos corregir al transeúnte, ni cambiar su ritmo, pero éste debe ser revulsionado en forma constante por propuestas nuevas basadas en claves mínimas". Esta política no surge a través de un modelo pedagógico que intente enseñar sobre las desigualdades, inequidades e injusticias del mundo ("no debemos corregir al transeúnte ni cambiar su ritmo"), un patrón que fue típico de la época, sino de un modo menos explícito y más complejo que Vigo piensa a partir de la revulsión. Este tipo de relación entre arte y política es, entonces, siempre móvil e inestable, porque depende de las normas sociales, culturales y políticas de un momento dado y de las relaciones que se establezcan entre estos campos.

\footnotetext{
${ }^{19}$ Ibidem, p 166.

${ }^{20}$ Ibid, p. 167
} 


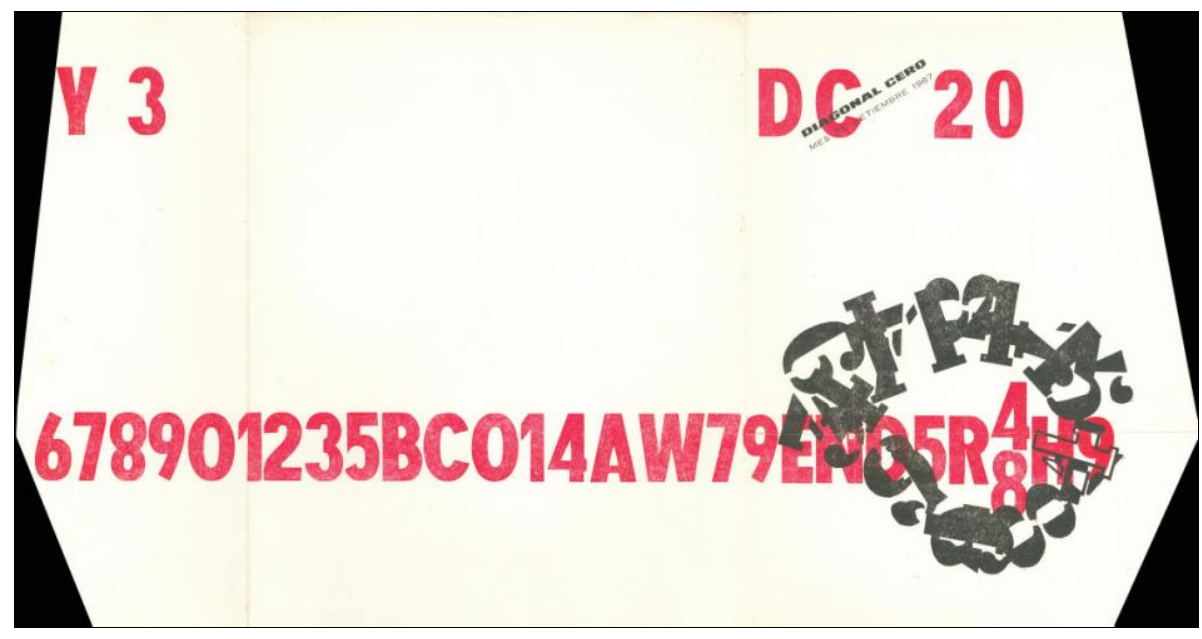

- Fig. 1. Portada desplegada de Diagonal Cero n 23, 1967. Archivo del Centro de Arte Experimental Vigo.

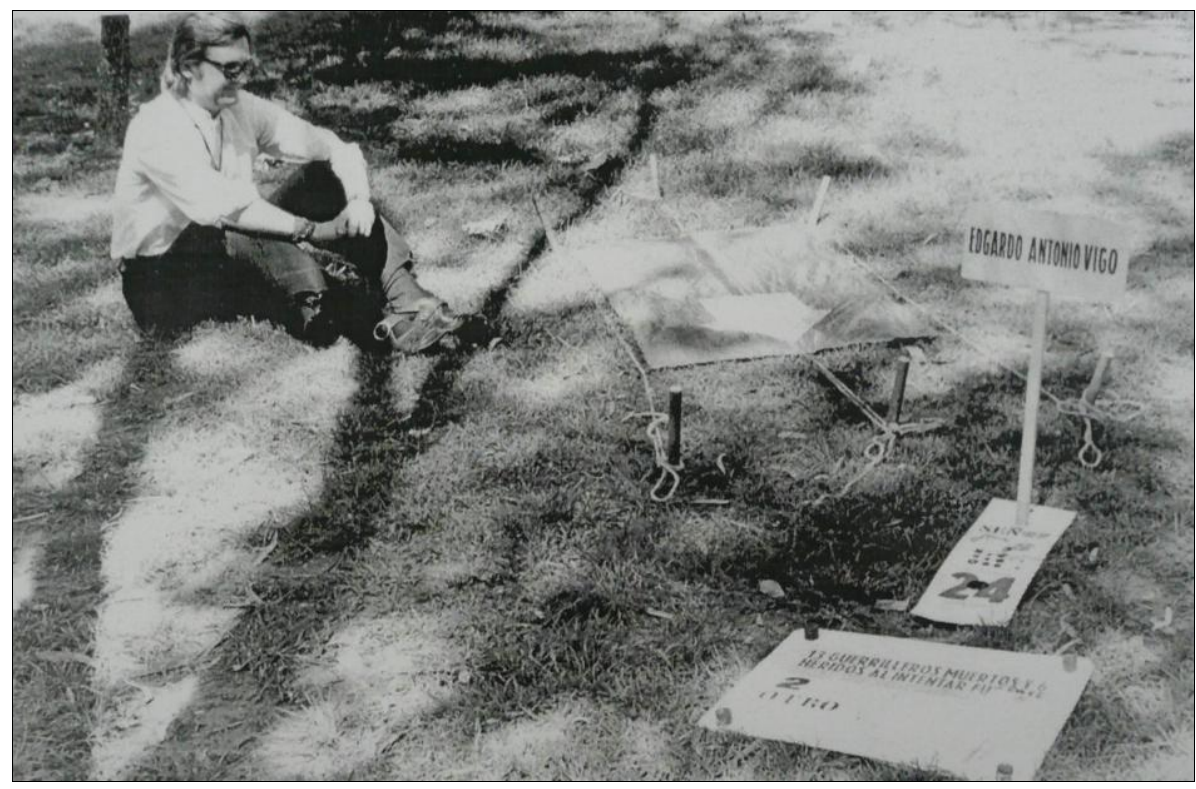

- Fig. 2. Fotografía del Señalamiento 11: Souvenir del dolor. Edgardo Antonio Vigo, 1972. Archivo del Centro de Arte Experimental Vigo. 


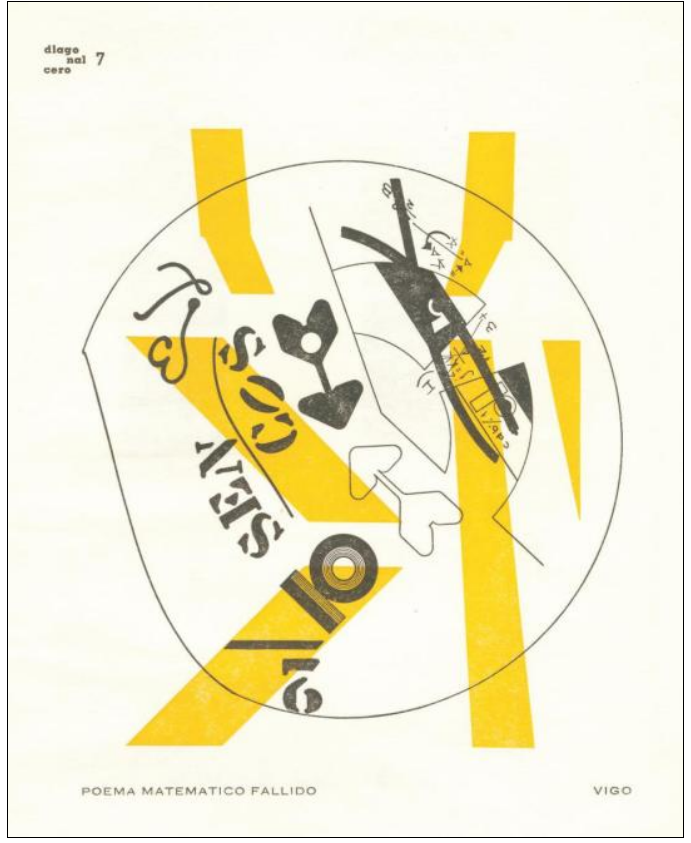

- Fig. 3. Edgardo Antonio Vigo. Poema matemático fallido, 1966. Archivo del Centro de Arte Experimental Vigo.

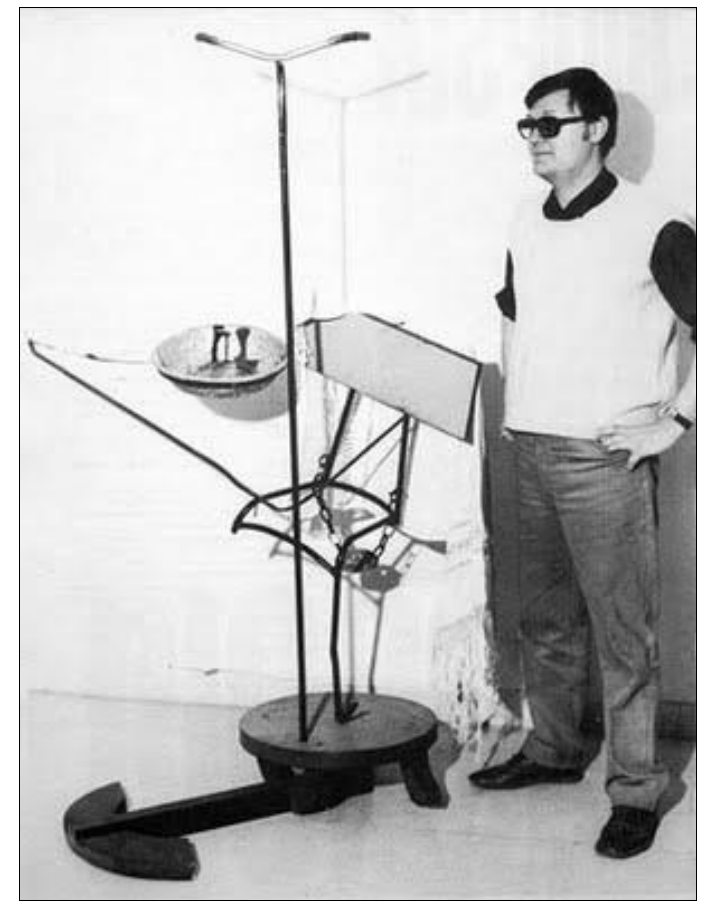

- Fig. 4. Edgardo Antonio Vigo. Palanganómetro mecedor (que no se mece) para críticos de arte, 1964. Archivo del Centro de Arte Experimental Vigo.

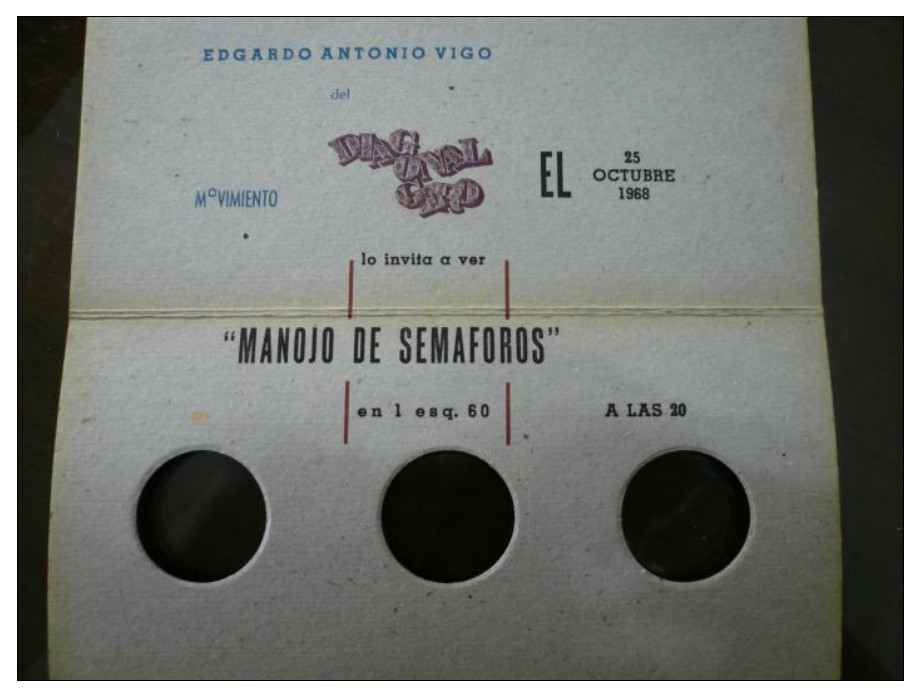

- Fig. 5. Edgardo Antonio Vigo. Invitación para ver Manojo de Semáforos, 1968. Archivo del Centro de Arte Experimental Vigo. 